\title{
Case study modelling for an ettringite treatment process
}

\author{
C Germishuizen', S Franzsen ${ }^{2}$, H Grobler ${ }^{2}$, GS Simate ${ }^{1,3}$ and CM Sheridan ${ }^{1,3}$ \\ 'Industrial and Mining Water Research Unit, School of Chemical and Metallurgical Engineering, University of the Witwatersrand, \\ Johannesburg, South Africa \\ ${ }^{2}$ Miwatek, P/Bag X29, Gallo Manor 2052, Johannesburg, South Africa \\ ${ }^{3}$ Centre in Water Research and Development, University of the Witwatersrand, Johannesburg, P/Bag 3, Wits 2050, South Africa
}

\begin{abstract}
Several technologies have been developed to treat acid mine drainage (AMD) and attention is shifting towards the removal of sulphate. The formation of ettringite, a hydrous calcium aluminium sulphate mineral, is an option to treat AMD and can reduce the sulphate concentration to well below the discharge specifications. The process modelled in this study includes the formation of ettringite and the recovery of gibbsite through the decomposition of recycled ettringite. The modelling of this process was done using PHREEQC and the results presented in this paper are based on the outcome of different case studies that investigated how the process is affected by a change in parameters. These include, changing the feed water $\mathrm{pH}$, altering the split fractions in the hydrocyclone for the gibbsite recovery and varying the $\mathrm{pH}$ for ettringite formation.
\end{abstract}

Keywords: acid mine drainage, ettringite, sulphate, PHREEQC

\section{INTRODUCTION}

South Africa is the $30^{\text {th }}$ driest country in the world with its water resources termed as scarce and extremely limited (Government Communication and Information System, 2015). The protection and sustainability of South Africa's water resources are, therefore, crucial. The Water for Growth and Development Framework, (DWAF, 2009) stipulated that the pollution of water resources can be attributed to the impact of mining activities, poor agricultural practices, urbanisation and industry-related activities.

Whereas the mining sector is a key contributor to the South African economy, it is also a major consumer of water and the production of acid mine drainage (AMD) from abandoned mines poses a threat to the water quality if it seeps into the groundwater supply or if it enters the surface water environment. This presents a challenge in reconciling the need for growth with the protection and sustainability of water resources, whilst still cultivating the economic benefit gained from the mining sector (DWAF, 2009).

AMD is a result of the oxidation of sulphide-containing ores (such as pyrite) from mining activities, due to the increase in exposure of these minerals to water, air and microorganisms (Simate and Ndlovu, 2014). AMD is characterised by a low $\mathrm{pH}$ and the acidity of the water liberates metals, including toxic metals and radionuclides, from the rocks with which it interacts. Furthermore, the sulphate content in AMD is high (Inter-Minesterial Committee, 2010). The discharge of sulphate increases the salinity of the receiving water bodies and contributes considerably to the total dissolved solids in mineimpacted water (Liang et al., 2015).

The elevation in sulphate concentration levels is leading to more stringent regulations as an inevitable consequence, in

This paper was originally presented at the 2016 Water Institute of Southern Africa (WISA) Biennial Conference, Durban, 15-19 May 2016.

* To whom all correspondence should be addressed.

일 +27117177592;

e-mail: craig.sheridan@wits.ac.za

Received 24 April 2017, accepted in revised form 10 January 2018. order to ensure that sulphate levels are kept within acceptable limits (Lorax Environmental, 2003). Although sulphate has not been of significant importance due to its relatively low toxicity compared to other contaminants, the increase in the salinity of the receiving water bodies is a cause for concern as it can make the water unfit for human consumption, unsuitable for industrial use and inhospitable to aquatic life (Smit, 1999). The South African Water Quality Guidelines list the target water quality for industrial use as $<500 \mathrm{mg} / \mathrm{L} \mathrm{SO}_{4}^{2-}$ (DWAF, 1996). The World Health Organisation's Sulphate in Drinking Water Guidelines conclude that there is no proposed health-based guideline for sulphate in drinking water. The guidelines do, however, state that concentration levels of 1 000-1 $200 \mathrm{mg} / \mathrm{L}$ will cause laxative effects and complaints are likely to arise with regards to the taste of water when sulphate concentration levels exceed $500 \mathrm{mg} / \mathrm{L}$. The South African National Standard for drinking water (SANS 241, 2011) lists the aesthetic limit of sulphate $\left(\right.$ as $\mathrm{SO}_{4}^{2-}$ ) as $\leq 250 \mathrm{mg} / \mathrm{L}$.

Various technologies have been developed to reduce sulphate in contaminated water; however, many of these technologies are expensive and cannot always address the problem in its entirety. Conventionally, lime precipitation reduces sulphate concentrations through the precipitation of gypsum. At gypsum equilibrium, which is typically only approached by lime precipitation technologies, the sulphate concentration is still well above limits proposed by discharge guidelines. Therefore, further treatment is required.

The formation of ettringite as a precipitate is another technique that can be used to treat mine-impacted water and has the capability of achieving sulphate concentrations that adhere to potable water and effluent discharge guidelines. Ettringite represents a group of acicular calcium aluminate hydrates (Damons and Petersen, 2002). The crystal structure of ettringite is illustrated in Figure 1 and its parallel columns consist of $\mathrm{Ca}^{2+}, \mathrm{Al}^{3+}$ and $\mathrm{OH}^{-}$structured units of $\left[\mathrm{Ca}_{6} \mathrm{Al}_{2}(\mathrm{OH})_{12} \cdot 24 \mathrm{H}_{2} \mathrm{O}\right]^{6+}$ (Sapsford et al., 2015). The channels between these columns are made up of $\mathrm{SO}_{4}^{2-}$ and water (Damons and Petersen, 2002).

The precipitation reaction of ettringite is given by the following reaction (Smit, 1999):

$$
\begin{aligned}
6 \mathrm{Ca}^{2+}+3 \mathrm{SO}_{4}^{2-}+ & 2 \mathrm{Al}(\mathrm{OH})_{3}+37 \mathrm{H}_{2} \mathrm{O} \rightarrow \\
& 3 \mathrm{CaO} \cdot 3 \mathrm{CaSO}_{4} \cdot \mathrm{Al}_{2} \mathrm{O}_{3} \cdot 31 \mathrm{H}_{2} \mathrm{O}+6 \mathrm{H}_{3} \mathrm{O}^{+}
\end{aligned}
$$




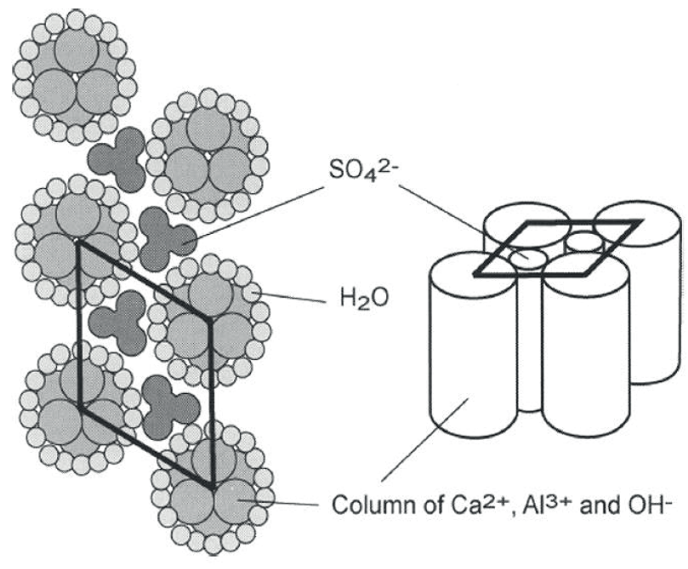

Figure 1

Schematic of the ettringite crystal (Johnson, 2004)

Ettringite is stable above a $\mathrm{pH}$ of 10.7; therefore, lime is added to ensure the optimum conditions for ettringite precipitation. Ettringite can be stable at $\mathrm{pH}$ values $<10.7$; however, this only occurs in association with gypsum and aluminium hydroxide $\left(\mathrm{Al}(\mathrm{OH})_{3}\right)$ and ettringite completely dissolves around a near-neutral $\mathrm{pH}$. Figure 2 shows the stability region of ettringite in alkaline environments.

The formation of ettringite requires the aluminium to be present as the amphoteric species $\mathrm{Al}(\mathrm{OH})_{4}$, and at a $\mathrm{pH}$ below 10.3, aluminium exists predominantly as amorphous aluminium hydroxide (gibbsite). Therefore, the stability of ettringite formation is $\mathrm{pH}$-dependent.

The drawback of using the existing ettringite technology to decrease sulphate levels in mine waters is the high operating cost, which mainly relates to the use of aluminium as a reagent. Aluminium recycling and recovery has been evaluated in some processes and it has been found that aluminium recycling requires a large amount of sulphuric acid to facilitate the dissolution of ettringite, and increases the amount of residue requiring disposal. Moreover, the ettringite crystal growth can only be obtained at a high $\mathrm{pH}( \pm 11.5)$, thus requiring a substantial amount of lime (Lorax Environmental, 2003).

There are currently three standard sulphate removal processes that involve ettringite precipitation. The first method, the SAVMIN process, has the disadvantage of high lime requirements, complicated process control and high gypsum crystallisation requirements. The second process, the Cost Effective Sulphate Removal (CESR) process uses a proprietary reagent and produces a large amount of sludge (Lorax Environmental, 2003). The Outotec Ettringite Process, the third method, uses sodium aluminate as a reagent and is reported to have faster kinetics of ettringite formation (Nevatalo et al., 2014). However, in a study done by Liang et al. (2015) it was pointed out that the drawbacks of the Outotec Ettringite Process include large amounts of sludge generated and an increase in the sodium concentration in the treated effluent.

\section{PHREEQC model}

Miwatek developed an equilibrium-based process model that uses PHREEQC, a computer program that was developed by the US Geological Survey to perform a wide range of geochemical calculations that are based on equilibrium

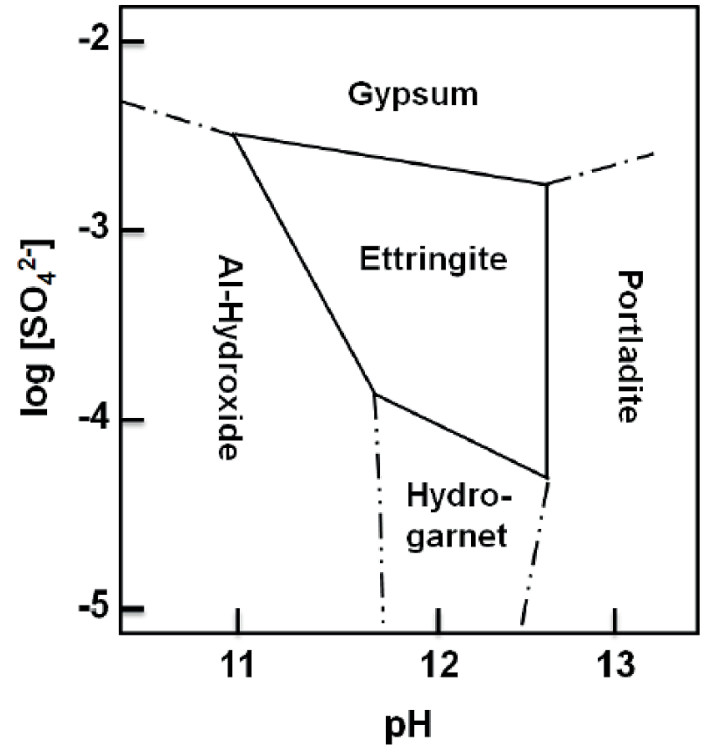

Figure 2

Ettringite stability in alkaline environments (Hampson and Bailey, 1982)

chemistry of aqueous solutions. The geochemical calculations include aqueous speciation and saturation indices, batch reactions and one-dimensional transport, reversible and irreversible reactions, surface complexation, ion exchange, kinetically-controlled reactions and inverse modelling. Version 3 of the program was released with the Microsoft component object model (COM) module to enable a COM server interface with correspondingly capable software (Charlton and Parkhurst, 2011). The ettringite process was modelled using a continuous substitution algorithm programmed in Microsoft's Visual Basic for Applications (VBA) and utilised the COM interface for geochemical calculations.

This paper evaluates the results of different case studies simulating an ettringite treatment process. The equilibriumbased process model Miwatek developed using PHREECQ predicted the process outcomes of various scenarios. The approach to equilibrium was specified as assumed saturation ratios of the selected equilibrium phases. In order to connect the work presented here with equipment and process design of the ettringite treatment process, experimental work is required to determine the precipitation rates that support the equilibrium-based modelling.

The key focus of simulating this process is to provide an ettringite treatment technology that can potentially be a feasible solution to treat AMD and to identify important process parameters. The ettringite treatment process and case studies are described and discussed in the subsequent sections.

\section{MATERIALS}

\section{Material acquisition}

The feed water composition used in the model was based on a sample of AMD collected from the Western Basin in Randfontein. High alumina cement (HAC) was supplied by Kerneos, a calcium aluminate technology company, and lime was obtained from SAKG. The reagent compositions used in the model are defined in Table 1. 


\section{METHODS}

\section{Process description}

The ettringite process flow diagram used for simulation is illustrated in Figure 3. The process has three principal processing stages followed by a $\mathrm{pH}$ adjustment step.

A portion of the ettringite sludge from the ettringite precipitation reactor, Reactor 3 , is recycled and mixed with the feed water in the ettringite dissolution reactor, Reactor 1 to dissolve ettringite. If the acidity and/or the metal concentration in the feed water is high enough, sufficient ettringite will be dissolved. Ettringite decomposition is the reverse of ettringite formation and forms the gibbsite for recycle. The solids formed in Reactor 1 are not separated and are transferred to the gypsum precipitation reactor, Reactor 2 , where lime is added. The calcium and sulphate in the ettringite and most of the sulphate in the feed water will precipitate upon reaching gypsum saturation levels.

The aluminium can be recycled from the ettringite sludge without the use of an acid addition step. Instead, the process exploits the acidic nature of the feed waste water in conjunction with the typically high iron and other multi-valent metal content. Recycling the ettringite sludge in this manner causes aluminium (as gibbsite) to be present in significant quantities in the gypsum sludge. Therefore, the sludge generated after the gypsum precipitation reactor, Reactor 2, will contain aluminium for recovery to minimise all possible losses from the process. Hydrocyclone technology is used to separate the gypsum from both the aluminium hydroxide and the other metal hydroxides. The resultant aluminium-rich slurry (hydrocyclone overflow) is

\begin{tabular}{|l|c|c|c|}
\hline \multicolumn{5}{|c|}{ TABLE 1 } \\
\hline $\mathrm{HAC}$ & Mass \% & Lime & Mass \% \\
\hline $\mathrm{Al}_{2} \mathrm{O}_{3}$ & 36.6 & $\mathrm{CaO}$ & 93.9 \\
\hline $\mathrm{CaO}$ & 50.5 & $\mathrm{Al}$ & 0.2 \\
\hline $\mathrm{SiO}_{2}$ & 4.9 & $\mathrm{MgO}$ & 1.3 \\
\hline $\mathrm{Fe}_{2} \mathrm{O}_{3}$ & 8.0 & $\mathrm{SiO}_{2}$ & 4.3 \\
\hline & & $\mathrm{Fe}$ & 0.3 \\
\hline
\end{tabular}

returned to the final reactor where it is brought into contact with the remaining sulphate, $\mathrm{HAC}$ and lime to once more precipitate ettringite. One of the features of the growth process for ettringite crystals is its ability to incorporate within its crystal structure substantial quantities of components such as arsenates, borates and chromates. The supernatant from the ettringite clarifier is injected with $\mathrm{CO}_{2}$ to adjust the $\mathrm{pH}$ and subsequently precipitate calcite and produce treated water.

This process configuration given in Fig. 3 was used in all three case study simulations. The different case studies were set up to investigate the process performance when various changes are made. The case studies are explained in the subsequent sections.

\section{Feed water composition}

The feed water parameters used in each of the three cases (1 to 3) are given in Table 2 .

\section{Case 1}

\section{Variable: Feed water $\mathrm{pH}$}

Case 1 modelled the outcome of varying the feed water $\mathrm{pH}$ on (i) the percentage of ettringite sludge that can be recycled to Reactor 1 and (ii) the reagent consumption in Reactor 3. The decrease in the feed water $\mathrm{pH}$ is achieved by increasing the concentration of sulphate in the feed water. The $\mathrm{pH}$ for Cases 1 (A) - (F) were 5.5, 4.5, 3.5, 2.5, 2 and 1.5, respectively, and the corresponding sulphate values were $3000,3027,3$ 058, 3339 , 4035 and $6394 \mathrm{mg} / \mathrm{L}$. The target $\mathrm{pH}$ for Reactors 1,2 and 3 were set at 9, 10.5 and 12, respectively. The sulphate discharge concentration was set at $250 \mathrm{mg} / \mathrm{L}$ for each case.

\section{Case 2}

\section{Variable: Hydrocyclone separation}

Case 2 modelled the result of the aluminium recovery via the hydrocyclone on the HAC consumption in Reactor 3 . The feed water composition is listed in Table 2 and was the same for cases 2 (A) - (F). The amount of gibbsite reporting to the hydrocyclone overflow was varied. The same reactor $\mathrm{pH}$ and sulphate discharge concentration, as set for Case 1, was attained in Case 2.

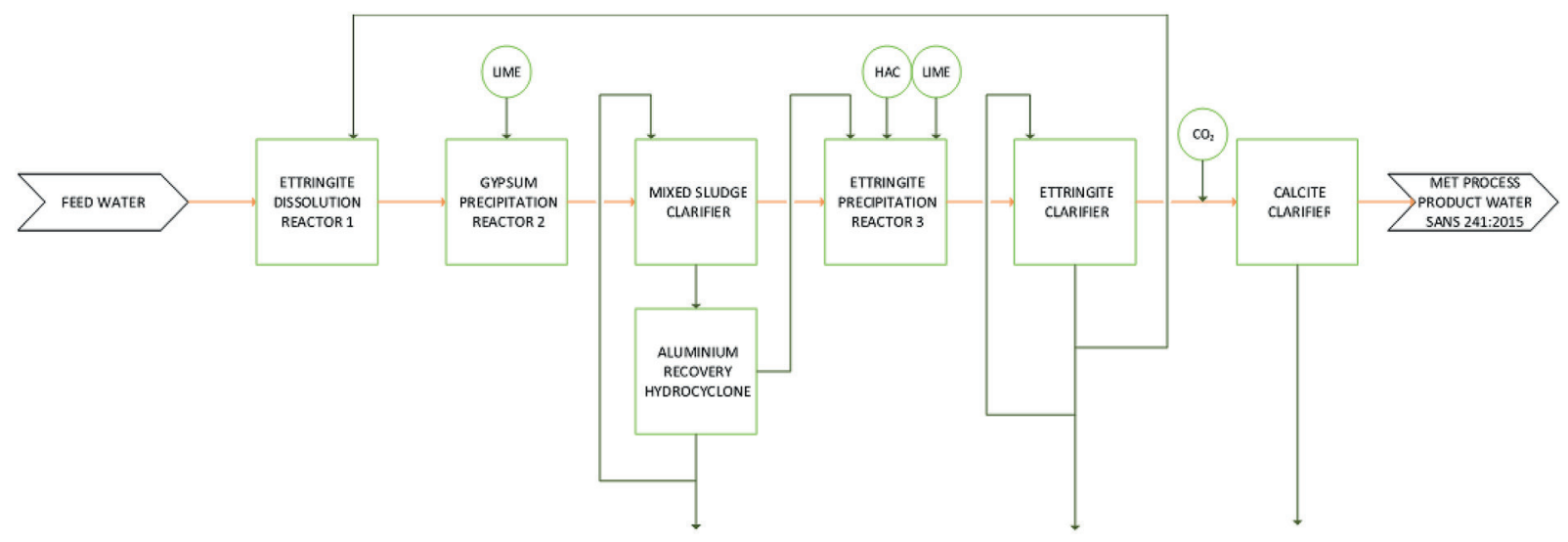

Figure 3

Ettringite block flow diagram 


\begin{tabular}{|c|c|c|c|c|c|c|c|c|c|}
\hline \multicolumn{10}{|c|}{$\begin{array}{l}\text { TABLE } 2 \\
\text { Feed water composition for Cases 1-3 }\end{array}$} \\
\hline \multirow{2}{*}{ Parameter } & \multirow{2}{*}{ Unit } & \multicolumn{6}{|c|}{ Case $1 \mathrm{~A}-\mathrm{F}$} & \multirow{2}{*}{ Case $2 \mathrm{~A}-\mathrm{F}$} & \multirow{2}{*}{ Case $3 \mathrm{~A}-\mathrm{F}$} \\
\hline & & $1 \mathrm{~A}$ & $1 B$ & $1 \mathrm{C}$ & 1D & $1 \mathrm{E}$ & $1 F$ & & \\
\hline Volumetric flow rate & $\mathrm{m}^{3} / \mathrm{h}$ & \multicolumn{6}{|c|}{41.7} & 41.7 & 41.7 \\
\hline $\mathrm{pH}$ & & 5.5 & 4.5 & 3.5 & 2.5 & 2 & 1.5 & 2.0 & 2.5 \\
\hline Aluminium (Al) & $\mathrm{mg} / \mathrm{L}$ & \multicolumn{6}{|c|}{0.2} & 0.2 & 0.2 \\
\hline Calcium (Ca) & $\mathrm{mg} / \mathrm{L}$ & \multicolumn{6}{|c|}{500.0} & 500.0 & 500.0 \\
\hline Chlorine $(\mathrm{Cl})$ & $\mathrm{mg} / \mathrm{L}$ & \multicolumn{6}{|c|}{49.0} & 49.0 & 49.0 \\
\hline Iron $(\mathrm{Fe})$ & $\mathrm{mg} / \mathrm{L}$ & \multicolumn{6}{|c|}{440.0} & 440.0 & 440.0 \\
\hline Potassium (K) & $\mathrm{mg} / \mathrm{L}$ & \multicolumn{6}{|c|}{12.0} & 12.0 & 12.0 \\
\hline Magnesium (Mg) & $\mathrm{mg} / \mathrm{L}$ & \multicolumn{6}{|c|}{198.0} & 198.0 & 198.0 \\
\hline Manganese (Mn) & $\mathrm{mg} / \mathrm{L}$ & \multicolumn{6}{|c|}{50.0} & 50.0 & 50.0 \\
\hline Sodium $(\mathrm{Na})$ & $\mathrm{mg} / \mathrm{L}$ & \multicolumn{6}{|c|}{120.0} & 120.0 & 120.0 \\
\hline Sulphate $\left(\mathrm{SO}_{4}\right)$ & $\mathrm{mg} / \mathrm{L}$ & 3000 & 3027 & 3058 & 3339 & 4035 & 6394 & 4035 & 3339 \\
\hline
\end{tabular}

\section{Case 3}

\section{Variable: Reactor 3 operating $\mathrm{pH}$}

Case 3 set the target $\mathrm{pH}$ for Reactors 1 and 2 at 9 and 10.5, respectively, and varied the $\mathrm{pH}$ of the ettringite precipitation reactor, Reactor 3 , to evaluate the outcome on (i) the sulphate discharge concentration, and (ii) the percentage solids formation of ettringite and gibbsite in Reactor 3. The HAC fed to the ettringite reactor was kept constant. The feed water composition used in the model is listed in Table 2 and remained the same for cases $3(\mathrm{~A})-(\mathrm{F})$.

\section{RESULTS AND DISCUSSION}

\section{Case 1}

\section{Sludge recycle}

Figure 4 shows the effect of the change in feed water $\mathrm{pH}$ on the percentage of ettringite sludge recycled. Case $1 \mathrm{~A}$ starts with a feed water $\mathrm{pH}$ of 5.5 and the ettringite dissolution reactor, Reactor 1 , is set to operate at a $\mathrm{pH}$ of 9 , which cannot be exceeded as the ettringite sludge will then not dissolve. The optimum $\mathrm{pH}$ for ettringite dissolution is 6.5 (Damons and Petersen, 2002). The $\mathrm{pH}$ should be low to ensure the sludge is unstable, which is why aluminium was conventionally recovered from the ettringite sludge by an acid addition step to lower the $\mathrm{pH}$. The motivation for recycling the ettringite sludge to Reactor 1 is to replace this conventional method and utilise the acidity of the feed water to liberate the aluminium by dissolving the ettringite. The results from Figure 4 illustrate that a feed water with a higher acidity allows for more ettringite sludge to be recycled, confirming that under the optimum acidic conditions, the feed water can facilitate ettringite dissolution. The model predicted that at a $\mathrm{pH}$ below 2 (Case $1 \mathrm{~F}$ ), all of the ettringite sludge is recycled, but that the dissolution reactor does not reach its intended target. It is not necessarily a problem that the target was not reached as the downstream process conditions were still satisfied. The higher acidic feed water required more recycled sludge to neutralise the feed water, since the decomposition of ettringite produces $\mathrm{OH}^{-}$ions and subsequently increases the $\mathrm{pH}$.

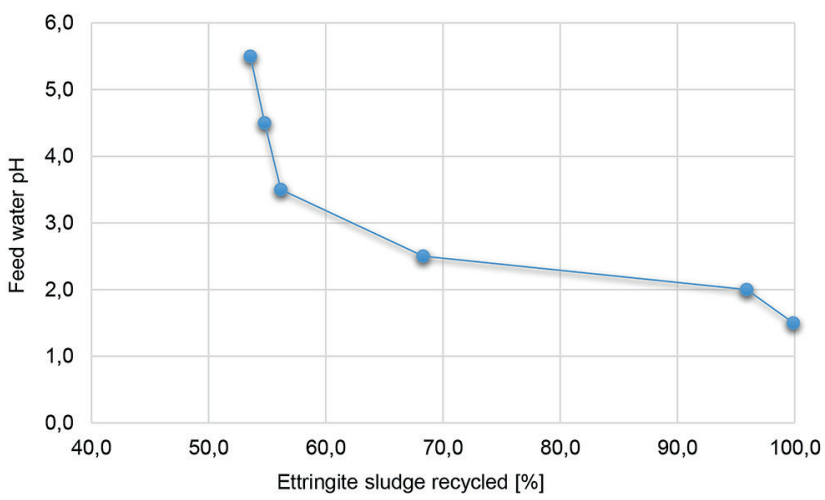

Figure 4

Ettringite sludge recycled vs feed water $\mathrm{pH}$

\section{Reagent composition}

The result of varying the feed water $\mathrm{pH}$ on the reagent consumption is displayed in Figure 5. Lime is added to the gypsum reactor to increase the $\mathrm{pH}$ to 10.5 to facilitate gypsum precipitation as well as precipitate the metal hydroxides. Lime is added in the ettringite precipitation reactor (Reactor 3 ) to increase the $\mathrm{pH}$ further and HAC is added as a source of aluminium to facilitate ettringite precipitation. From Table 3 and Figure 5, a decrease in the feed water $\mathrm{pH}$ shows an increase in lime consumption at both the gypsum and the ettringite reactor, but a decrease in HAC consumption. Once more, below a $\mathrm{pH}$ of 2 , the lime consumption increased, especially at the gypsum reactor as more lime was required to increase the $\mathrm{pH}$ as the previous reactor did not meet its target. The HAC consumption can be related to the feed water acidity having an impact on the amount of ettringite that can be recycled, which in turn determines the amount of aluminium available for recovery and hence the aluminium make up required for the ettringite precipitation reactor. $\mathrm{HAC}$ also contains $\mathrm{CaO}$, a component that can replace some of the lime requirements in the ettringite reactor, as illustrated by the fact that a decrease 
in $\mathrm{HAC}$ increases the lime requirements to the ettringite precipitation reactor.

Although it will be beneficial to recycle all of the ettringite sludge, in terms of minimising solid waste from the process, this should be weighed against the reagent consumption. The sulphate concentration entering the ettringite precipitation reactor, Reactor 3, is similar for all cases $(\mathrm{A})$ - (F) therefore, the removal of sulphate to form ettringite and the aluminium consumption should theoretically be similar. The decrease in the HAC consumption can be related to the ettringite sludge recycled and the gibbsite subsequently separated and recovered.

\section{Case 2}

The HAC consumption in the ettringite precipitation reactor was predicted as a function of the hydrocyclone efficiency determining the fraction of gibbsite that reports to the overflow. Case 2 used a feed water with a $\mathrm{pH}$ of 2 (feed composition from Case 1 (E)). Recycling of the ettringite sludge allows for the decomposition of ettringite to $\mathrm{Al}(\mathrm{OH})_{3}$ (Eq. 1) which is present in the sludge from the gypsum precipitation reactor. The sludge sent to the hydrocyclone is separated and the hydrocyclone overflow reports to the ettringite precipitation reactor, thus enabling aluminium to be recovered from the process. Figure 6 displays the expected trend, since an increase in the fraction of gibbsite to the ettringite precipitation reactor leads to a decrease in HAC consumption as the recovered aluminium decreases the external aluminium make-up source needed.

Table 4 indicates that as the recovery of gibbsite increases the amount of lime required in the process increases and the HAC consumption decreases. The HAC has acid-neutralising power since it contains a portion of lime; therefore, as less HAC is needed with a higher recovery, more lime will be required overall. The ettringite sludge is different for the cases where the gibbsite recovered replaced the amount of external aluminium needed, as it contains fewer impurities introduced into the process from the HAC. The increase in gibbsite recovery shows how the process will react in terms of reagent consumption and how the nature of the ettringite sludge formed impacts the recycling requirements of the process.

\section{Case 3}

Case 3 used a feed $\mathrm{pH}$ of 2.5 (Case $1 \mathrm{D}$ feed composition), varied the ettringite precipitation reactor, Reactor $3, \mathrm{pH}$ and kept the HAC consumption constant to predict its outcome on the sulphate discharge concentration (i.e., the amount of ettringite formed). Figure 7 illustrates the results. Ettringite formation is highly $\mathrm{pH}$-dependent and forms within an optimum $\mathrm{pH}$ range; the result of this case study confirms

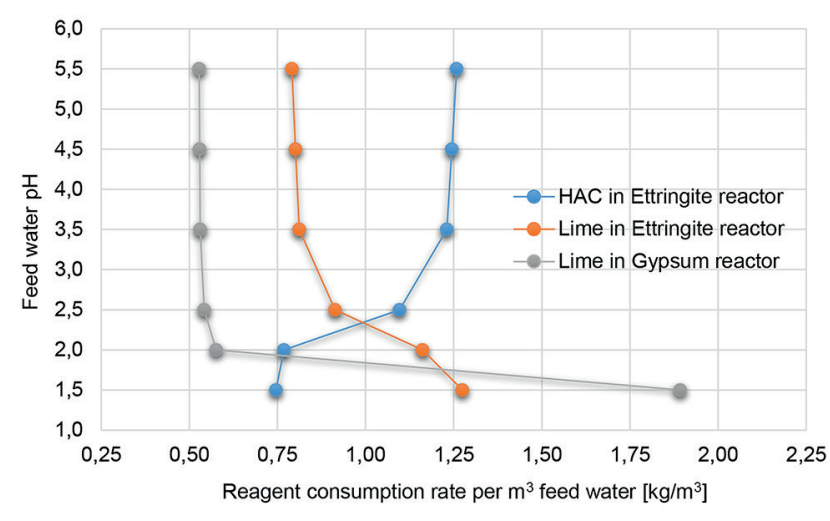

Figure 5

Reagent consumption vs feed water $\mathrm{pH}$

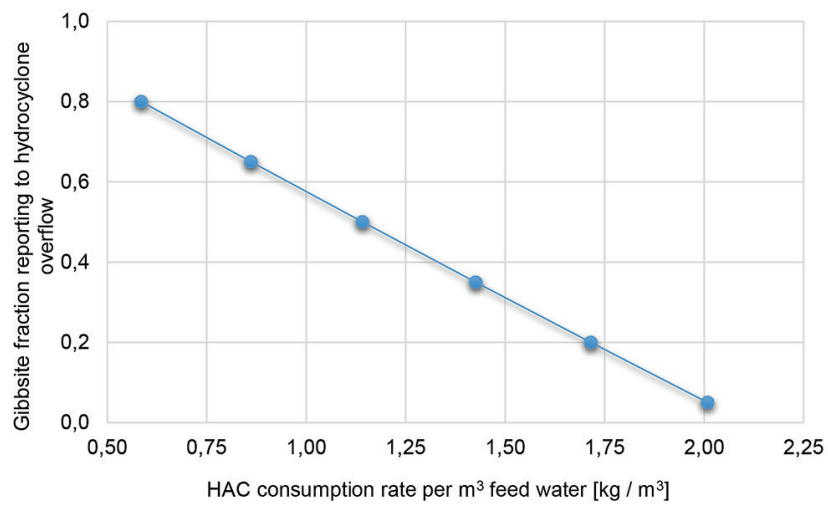

Figure 6

HAC consumption vs gibbsite separation efficiency

\begin{tabular}{|l|l|c|c|c|c|c|c|}
\hline \multicolumn{7}{|c|}{$\begin{array}{c}\text { TABLE 3 } \\
\text { Reagent feed }\end{array}$} \\
\hline & & Case 1 A & Case 1 B & Case 1 C & Case 1 D & Case 1 E & Case 1 F \\
\hline Lime to gypsum reactor & $\mathrm{kg} / \mathrm{m}^{3}$ feed water & 0.53 & 0.53 & 0.53 & 0.54 & 0.58 & 1.89 \\
\hline Lime to ettringite reactor & $\mathrm{kg} / \mathrm{m}^{3}$ feed water & 0.79 & 0.80 & 0.81 & 0.91 & 1.16 & 1.27 \\
\hline HAC to ettringite reactor & $\mathrm{kg} / \mathrm{m}^{3}$ feed water & 1.26 & 1.25 & 1.23 & 1.10 & 0.77 & 0.75 \\
\hline
\end{tabular}

\begin{tabular}{|l|l|c|c|c|c|c|c|}
\hline \multicolumn{9}{|c|}{ TABLE 4 } \\
\hline & & Case 2 A & Case 2 B & Case 2 C & Case 2 D & Case 2 E & Case 2 F \\
\hline Lime to gypsum reactor & $\mathrm{kg} / \mathrm{m}^{3}$ feed water & 0.53 & 0.54 & 0.55 & 0.56 & 0.57 & 0.58 \\
\hline Lime to ettringite reactor & $\mathrm{kg} / \mathrm{m}^{3}$ feed water & 0.50 & 0.66 & 0.81 & 0.96 & 1.11 & 1.26 \\
\hline HAC to ettringite reactor & $\mathrm{kg} / \mathrm{m}^{3}$ feed water & 2.01 & 1.72 & 1.43 & 1.14 & 0.86 & 0.59 \\
\hline Ettringite sludge recycled & $\%$ & 98.7 & 98.0 & 97.4 & 96.7 & 96.11 & 95.5 \\
\hline
\end{tabular}




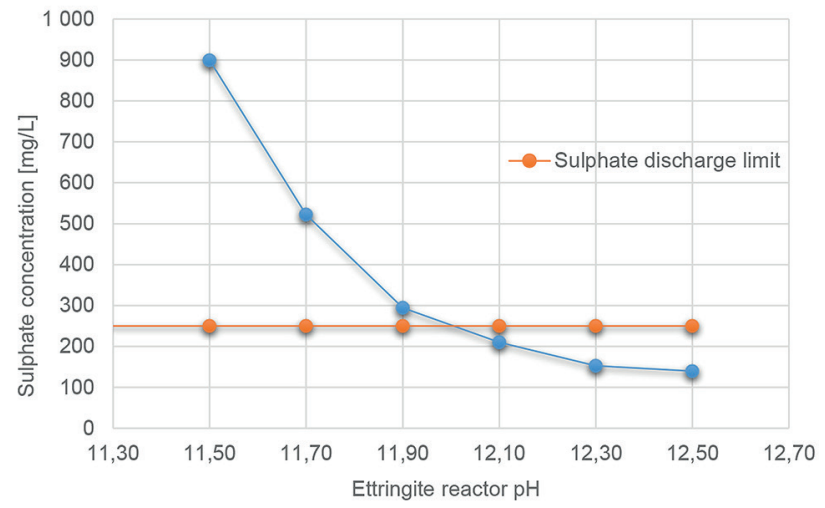

Figure 7

Sulphate discharge concentration vs ettringite precipitation reactor (Reactor 3) $\mathrm{pH}$

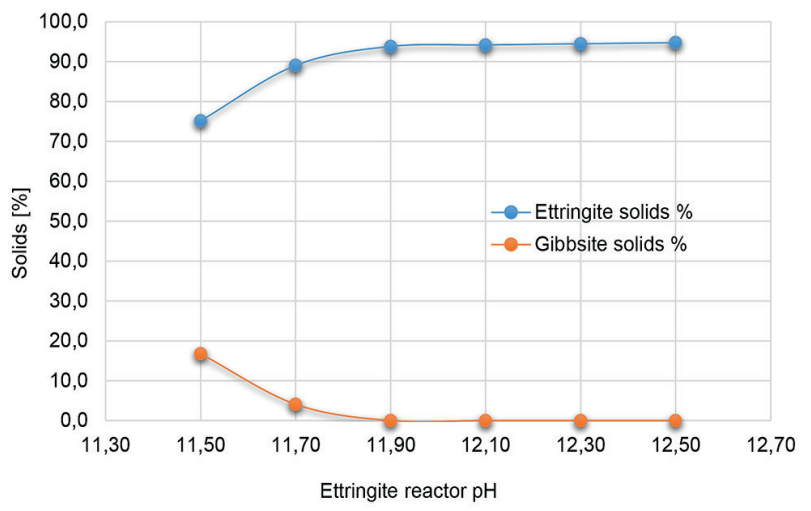

Figure 8

Ettringite and gibbsite solids formation vs. ettringite reactor $\mathrm{pH}$

this $\mathrm{pH}$ dependency by showing how narrow this $\mathrm{pH}$ range is. The stability of ettringite can be enhanced in the presence of additional alkaline components (Damons and Petersen, 2002). As less lime is added to achieve the lower $\mathrm{pH}$ conditions of the reactor, less alkaline conditions and less calcium are introduced into the process. The $\mathrm{pH}$ has a significant effect on the sulphate discharge concentration achievable through the amount of ettringite formed. Figure 8 also supports this; as the reactor tends to more optimum $\mathrm{pH}$ conditions, the formation of ettringite is favoured compared to the precipitation of gibbsite.

\section{CONCLUSIONS}

The equilibrium-based modelling of the ettringite treated process (Fig. 3), through the geochemical calculations of PHREEQC, indicated that it is possible to treat AMD to within typical sulphate discharge limits.

Furthermore, the model indicated how the process responded to changes in several parameters and yielded results useful for process optimisation. The model is insensitive to the approach to equilibrium achieved and the rate at which the assumed approach is achieved. The continuation of this work will focus on implementing rate-based sub-models for the solid-liquid separation stages. Laboratory-scale experiments will be conducted to calibrate the rate-based precipitation submodels, as no truly predictive method exists for kinetic studies in precipitation, especially for mixed solids phases as present in this process.

The particle size distribution of the mixed sludge feed to the hydrocyclone is particularly important in the determination of gibbsite recovery to the overflow. Experimental work will further focus on correlating the particle size distribution and reactor conditions to the performance of the hydrocyclone with respect to gibbsite recovery.

The model indicated that highly acidic feed water has the potential to dissolve the ettringite sludge as an increase in the amount of ettringite sludge that can be recycled is observed for more acidic conditions. The decomposition of ettringite releases hydroxide ions and, therefore, neutralises the feed water and increases the $\mathrm{pH}$. This can provide a special application treatment option for highly acidic AMD. Furthermore, an increase in the sludge recycled allows for more aluminium that can be recovered, thus lowering the consumption of the aluminium reagent make up. The source of aluminium used in this model is a low purity form of aluminium, i.e., HAC. When HAC is used, the other components in the cement can provide a substitute for a significant portion of the necessary lime input that is needed for ettringite precipitation. Therefore, recycling more ettringite sludge lowers the HAC make up and increases the lime consumption.

The increase in the fraction of gibbsite recovered via the hydrocyclone separation decreases the amount of HAC consumed since the gibbsite fraction is related to the aluminium recovery available. Thus, the same conclusion as above is reached, i.e., more aluminium recovered decreases the external aluminium reagent make up.

The importance of $\mathrm{pH}$ control on the ettringite precipitation reactor was highlighted by the fact that lowering the reactor operating $\mathrm{pH}$ resulted in less ettringite being formed for the same feed conditions and HAC reagent feed. In addition, the sulphate discharge concentrations showed significant differences for such a narrow $\mathrm{pH}$ range of between 11.5 and 12.5. The amount of ettringite solids formed at these various $\mathrm{pH}$ ranges supports the importance of $\mathrm{pH}$ control and confirmed the strong $\mathrm{pH}$-dependency of ettringite formation.

\section{ACKNOWLEDGEMENTS}

The authors would like to acknowledge, Miwatek, the National Research Foundation and the Water Research Commission for their support and funding of this project.

\section{REFERENCES}

CHARLTON SR and PARKHURST DL (2011) Modules based on the geochemical model PHREEQC for use in scripting and programming languages. Comput. Geosci. 37 1653-1663. https:// doi.org/10.1016/j.cageo.2011.02.005

DAMONS R and PETERSEN F (2002) An Aspen model for the treatment of acid mine water. Eur. J. Miner. Process. Environ. Protect. 2 69-81.

DWAF (Department of Water Affairs and Forestry, South Africa) (1996) The South African Water Quality Guidelines Volume 3: Industrial Use. ( $2^{\text {nd }}$ edn). DWAF, Pretoria.

DWAF (Department of Water Affairs and Forestry, South Africa) (2009) Water for Growth and Development Framework. ( $7^{\text {th }}$ edn). DWAF, Pretoria.

GOVERNMENT COMMUNICATION AND INFORMATION SYSTEM (2015) South African Yearbook 2013/2014: Water Affairs. URL: http:// www.gcis.gov.za/sites/www.gcis.gov.za/files/docs/resourcecentre/ yearbook/2013-4Water_Affairs.pdf (Accessed 21 June 2015).

HAMPSON CJ and BAILEY JE (1982) On the structure of some 
precipitated calcium alumino-sulphate hydrates. J. Mater. Sci. 17 3341-3346. https://doi.org/10.1007/BF01203504

INTER-MINISTERIAL COMMITTEE (2010) Mine water management in the Witwatersrand gold fields with special emphasis on acid mine drainage. A Report to the Inter-Ministerial Committee on Acid Mine Drainage, South Africa.

JOHNSON CA (2004) Cement stabilization of heavy-metal-containing wastes. Geological Society, London, Special Publications 236 595-606. https://doi.org/10.1144/GSL.SP.2004.236.01.33

LIANG HC, TAMBURINI J and JOHNS F (2015) Designing a mine water treatment facility to remove sulfate. In: $10^{\text {th }}$ International Conference on Acid Rock Drainage \& IMWA Annual Conference, 21-24 April 2015, Santiago, Chile.

LORAX ENVIRONMENTAL (2003) Treatment of sulphate in mine effluents. International Network for Acid Prevention, Utah.

NEVATALO LM, VAN DER MEER T, MARTIKAINEN M, MÄKINEN AE and TANNINEN J (2014) Enhanced ettringite process - a novel solution for sulfate removal. In: Hydrometallurgy Conference, 22-25 June 2014, Victoria, Canada.

SABS (South African Bureau of Standards) (2011) South African National Standards. Drinking water. Part 1: Microbial, physical, aesthetic and chemical determinants. SABS, Pretoria.

SAPSFORD D, TUFVESSON S, COULTON R, PENNY T and WILLIAMS K (2015) The effect of aluminium source and sludge recycling on the properties of ettringite formed during water treatment. In: $10^{\text {th }}$ International Conference on Acid Rock Drainage \& IMWA Annual Conference, 21-24 April 2015, Santiago, Chile.

SIMATE GS and NDLOVU S (2014) Acid mine drainage: Challenges and opportunities. J. Environ. Chem. Eng. 2 1785-1803. https://doi. $\operatorname{org} / 10.1016 /$ j.jece.2014.07.021

SMIT JP (1999) The treatment of polluted mine water. In: International Mine Water Association Congress, 13-17 September 1999, Sevilla, Spain. 